\title{
Perceptions and Strategies of Effective Coaching Leadership: A Qualitative Investigation of Professional Coaches and Players
}

\begin{abstract}
Andrew Bennie ${ }^{1}$ and Donna O'Connor ${ }^{2}$
${ }^{1}$ School of Science and Health, University of Western Sydney, Building BD, Level 1, Room 24b | Werrington South Campus, Locked Bag 1797 | Penrith South DC NSW Australia | 2751 a.bennie@uws.edu.au

${ }^{2}$ Faculty of Education and Social Work, The University of Sydney, Building A35, Room 447, NSW, Australia 2006

[Received July 20, 2012; Accepted November 8, 2012; Published online November 14, 2012]

This paper outlines the findings from a qualitative investigation of the perceptions about, and strategies of, effective coaching leadership within three male Australian professional team sport contexts. Data collection involved semi-structured observations and interviews with coaches and players from professional cricket, rugby union and rugby league teams at training and competition venues in Australia. Data analysis revealed three major properties that underpin perceived effective coach leadership-(1) Develop a personalised approach, (2) Delegate responsibilities and (3) Decision-making. The findings showed that coaches in these professional sport settings possessed their own personal approach to leadership, yet develop a leadership style that resonates with the ideals of support staff and players. The results also demonstrated how a player-centred approach to coach leadership was more highly valued than the traditional, coachcentred approach within these professional contexts. The implications for coaching practice are discussed in relation to previous leadership and coaching literature.
\end{abstract}

Keywords: leadership, effective coaching, perceptions, qualitative research

\section{Introduction}

Over time, coaches, players, and researchers have regularly provided commentary about the qualities, skills and characteristics of effective, good, expert or successful coaches. Early research provided clear frameworks for studying coach and athlete interactions (i.e., Smoll and Smith, 1989; Smoll et al., 1978) and the coach's leadership behaviour (i.e., Chelladurai, 1990; Chelladurai and Carron, 1978). Many studies have utilised either surveys or systematic observations to show how coaches' behaviours and leadership styles have a significant impact on athlete satisfaction, perceived competence and selfesteem (Côté and Gilbert, 2009). Perhaps the most pertinent information to emerge from this type of sports research is that the most effective coaches are able to modify their actions by incorporating the preferred and required leadership behaviours into how they actually behaved.

Although survey and observation research has been valuable for informing coach educators and sports practitioners about key athlete preferences for specific coaching behaviours, there may be further coaching variables not listed on the questionnaires (or observation schedules) that are important criteria for sport participants. In recent times, leadership research focused on the personal characteristics and philosophical foundations of effective coaches (Bennie and O'Connor, 2010; Vallée and Bloom, 2005) using qualitative methodologies. These studies were advantageous because they furthered our understanding about sport participants' perceptions of effective coaching leadership and the reasons why coaches behave and lead as they do in various coaching settings. This study extends previous research by incorporating observations during training and competition in association with interview data to build a more detailed contextual picture of leadership behaviours perceived to be effective in professional sport settings.

The ability to extract detailed information regarding coach and athlete opinions through qualitative interviews is a major advantage for research in the 
field of coaching. While some recent coaching studies have emerged from Europe (Jones et al., 2004) and North America (Vallée and Bloom, 2005), little is currently known about the leadership behaviours of professional coaches, and none include an entire sample of professional sportspeople from Australasia. Furthermore, a recent critical analysis of coach leadership and effectiveness models failed to identify any notion of athlete-centred coaching or empowerment objectives (see Vella et al., 2010) despite research findings that highlight the value of athlete empowerment (Kidman and Lombard, 2010). Consequently, the purpose of this study is to examine effective coaching leadership through observations and interviews with coaches and players from professional sports competitions in Australia.

\section{Methodology}

\subsection{Participants}

The sample included three professional sport teams from Australia. Six professional coaches (three head coaches and three assistant coaches) and 25 players who compete in the Super 15 Rugby (rugby union), National Rugby League, and the Sheffield Shield, One-day and Twenty-20 competitions (men's national cricket league) took part in the interview process with an additional seven full time coaches and 30 players who were observed during training or competition (total number of observation sessions $=41$ ). These players and coaches train and compete in Australia (and abroad) at the highest possible league level (e.g., national professional leagues) at the level below international competition (e.g., World Championship representation). For a more detailed description of the research context, see Bennie (2009).

\subsection{Data Collection}

The data collection process involved semi-structured observations (including detailed field notes) and semi-structured interviewing all of which were conducted by the chief author. During observations, coaching behaviours such as timing and type of coach instruction, feedback or management of the athletes were identified. To triangulate and strengthen the data collection procedure, semi-structured interviews were conducted (see Bennie, 2009) with par- ticipants following the observation sessions. When the participants were asked interview question one ("What do you think makes a coach effective?"), many responses related to the leadership style or coaching strategy coaches and players personally perceived as most effective. Coach leadership styles also emerged when participant coaches were asked to describe the main aim of their coaching program and the types of roles and responsibilities coaches delegated to assistant coaches, support staff, and players. The interviews and observations were conducted over a four month period in 2007-8 with interviews lasting approximately 45 minutes. In order to maintain anonymity, all participant names were changed to pseudonyms.

\subsection{Data Analysis}

The analysis of data in the current research involved analytic procedures based on the constant comparison methods (Côté et al., 1993). Following verbatim transcription of interview and observation notes, the first stage of analysis involves the creation of meaning units based on selected 'text segments' that contain one idea (Tesch, 1990). These were coded with a provisional descriptive name and when comparable information emerged, the same code was re-used. The meaning units were given tags when enlightening interview content emerged. For example, the meaning unit "... effective coaching comes down to less about over direction and more about facilitating in a nutshell"' (Ronnie, rugby union assistant coach) was assembled into the tag called Facilitator.

In the next analytic stage, properties were developed based on similar features to the initial level of analysis (Côté et al., 1993). Where similarities across each context existed, tags were assembled into a new property group. For example, the tags coded as Facilitator and Amiable dictator were grouped in the property called Develop a Personalised Leadership Approach while other tags such as Make Major Decisions and Assertive were allocated to the property entitled Decision Making. Further analysis of the data identified similarities between the property groups, which were then collated to make up the categories. In the case of the properties: Develop a Personalised Leadership Approach, Delegate Responsibility, Decision Making, all were linked in the Leadership category. 


\subsection{Establishing Trustworthiness}

The University of Sydney's Research Ethics Committee provided ethical approval to carry out this research. In the present study, observations were triangulated with data from interviews so that the meanings and interpretations of the players were compared to the coaches (and vice versa) to authenticate the interview data (Stake, 2000). Academic colleagues (i.e., Chief and Associate Supervisors, postgraduate peers) at the University of Sydney were consulted as the primary sources of reviewing, articulating ideas and evaluating research procedures (peer debriefing; Bloom, 1996). In order to satisfy the requirements of member checking (Côté and Sedgwick, 2003), participants' were provided with a full copy of interview transcripts and encouraged them to assess the information within the document. None of the participants requested changes to the data. To minimise concerns associated with dependability (Lincoln and Guba, 1985), a pilot study was conducted with an amateur rugby union team and throughout the research process, an audit trail (through a notebook-style collection of accounts) was kept to outline and authenticate how data was collected (confirmability; Merriam, 1998).

\section{Results}

The analysis process reduced the data from 953 raw data units to 314 that related to Leadership. Seven tags and three major properties were then assigned under the category of Leadership. The principal researcher used the terms from participants that best described each of the concepts as shown in Table 1.

Table 1 Tags and properties in the leadership category

\begin{tabular}{ll}
\hline \multicolumn{2}{c}{ Leadership Category } \\
\hline \multicolumn{1}{c}{ Tags } & \multicolumn{1}{c}{ Property } \\
\hline $\begin{array}{l}\text { Facilitator } \\
\text { Amiable dictator }\end{array}$ & $\begin{array}{l}\text { Develop a Personalised } \\
\text { Approach }\end{array}$ \\
\hline $\begin{array}{l}\text { Assign roles for players and coaches } \\
\text { Empowerment }\end{array}$ & Delegate Responsibilities \\
$\begin{array}{l}\text { Develop accountability and } \\
\text { decision-making skills }\end{array}$ & \\
\hline $\begin{array}{l}\text { Make major decisions } \\
\text { Assertive }\end{array}$ & Decision-making \\
\hline
\end{tabular}

\subsection{Develop a Personalised Approach}

The findings in this property revealed contrasting perspectives regarding the strategies that best reflect effective coaching. While Leopold (rugby league head coach) described himself as an "amiable dictator", the rugby union and cricket coaches focused on facilitating player development. For example, Ronnie (rugby union assistant coach) stated that "... effective coaching comes down to less about over direction and more about facilitating in a nutshell', while Cyrus (cricket head coach) suggested:

... the whole aim of my coaching is to end up not doing a lot because it's player-driven and if someone steps out of line, then the other blokes [players] are saying... "you're not working with us, what's your problem?",

The cricket and rugby union head coaches both believed that managing team dynamics and individual player needs are key aspects of their leadership. To achieve this, Cyrus (cricket head coach) claimed that he empowers coaches and players and encourages them to come up with solutions because he feels that he "can't do everything" so he aims to "just monitor, really". Rex (rugby union head coach) explained that empowerment is an effective leadership strategy as it means that other coaches can cover areas of the game where his knowledge was limited:

... head coaches can't really hope to be good at everything. They don't understand everything they won't necessarily be the best at everything. So you need to acknowledge your weaknesses and have people around you that are going to fill in the gaps.

Rex's comments provide significant insight into his role as head coach in professional rugby union. He acknowledged that each coach involved with a team brings certain expertise to the coaching program. The aim here is to acknowledge each coach's strengths and weaknesses and utilise their knowledge to help their players learn, develop and perform at an optimal level.

Supporting the ideas about empowerment from the interviews, observational data indicated that Rex (rugby union head coach) and Cyrus (cricket head coach) roamed around training, having delegated most training tasks to expert assistant coaches. Both mainly observed player action while facilitating during training sessions by occasionally getting involved in conducting an activity or providing feedback to 
the team. For example, during rugby union observation session 4 , the following was noted:

\subsection{7am-Split into units (Forwards and Backs)}

- Assistant Coach Forwards (ACF) takes forwards for high intensity lineout practice against the reserves (so it's contested and game like)

- ACF observes from side on, Head Coach (HC) from front on (e.g. sideline)

- HC mainly silent observation

- HC chats to captain individually (does this at times during the session, chats to individuals where he feels necessary)

This roaming and facilitative strategy was a highly valued strategy of the effective coach's role as Curtis (cricket player) and Robert (rugby union player) explained:

Being able to get around to players and just talk to them and just see how they're going and offer any advice whether it's technically or in any other sort of sense. Just to be able to help out in that sort of way, that's how I see the coach's role ... (Curtis)

... it makes the coach's job easier, 'cause he doesn't have to worry about all those little things and therefore he can do more work on analysing, putting things in place. (Robert)

Unlike the head coaches in rugby union and cricket, Leopold (rugby league head coach) carried out a more active role in leading his team. He regularly conducted training activities and provides concurrent commentary throughout each activity, even when one of his assistant or specialist staff were running an activity. Although the rugby league coaches indicated that they empowered assistant coaches and the players, Leopold (rugby league head coach) cautioned against giving players too much responsibility, particularly concerning team discipline:

... whether it's old fashioned or not... I don't believe a sporting club is a democracy. I hear of coaches with player leadership groups. I do not believe in that. I do not believe players should be judging other players. I believe players should lead other players and it naturally happens. The leadership comes from the coach. The coach and his staff lead the team and lead the club. Players want direction. They want input. I listen to my ... staff . . . I ask players for feedback... But I do not let players for instance set rules or, judge players for being late to training I just don't believe in it at all . . . you don't put the troops in charge of running the place...

Leopold believed that greater control was necessary in order to coach effectively. This aligns with his approach to coaching in what he described as more of a ". . . dictatorship but what you'd call an amiable dictator" who listens to staff and players but is ultimately responsible for making decisions, inspiring his players and leading the team. Interestingly, there was limited input from the rugby league players here with respect to the type of leadership style they preferred. They did however make comment on the types of responsibilities effective coaches delegate as shown in section 3.2 .

\subsection{Delegate Responsibilities}

Players and coaches agreed that the head coach sets the initial strategy for the team, yet empowers others to "micro-manage" (Ricardo, rugby union player) parts of the organisational, training and competition framework. This was a more recent phenomenon in coaching, a fact outlined by Leopold (rugby league head coach):

As a professional coach these days, you have staff who will run around and organise the nitty gritties [specific parts] of the session. It's changed over the years. There's no doubt that I would control everything when I first started. I would tell the trainer what to do. Now of course, you basically employ full time people, you have to empower them by, ... a after consultation of course, ... relying on them to do that type of thing for you.

Empowerment enabled an open and flexible environment in which players and support staff were delegated with tasks, for example, in planning for training, conducting parts of training sessions, and expressing ideas during meetings and training sessions. The leadership style of the head coach influenced what was delegated to players and coaches as Cyrus (cricket head coach) states:

... it's just allowing them to make decisions . . . at the beginning of the season I might bring a couple of blokes [players] in and ask them well 'what do you think of training?' or 'what do you think we need from here on in?' . . . just involving discussion with them and communication, that's what it's about . . . them taking a session ... 
Rather than abrogate responsibility, head coaches delegate tasks in order to increase player input, investment and commitment to the team's direction. The following observational data is a typical example of empowerment from the cricket context during the first observation session:

11.15am-Team meeting; Players split into batsmen and bowlers:

- All batsmen head into meeting room next door for 'round table' discussion about opposition bowlers, led by the captain.

- Captain asks players what they know about opposition bowlers and their bowling style.

- Each player given opportunity to voice opinion on strengths and weaknesses of opposition players.

- Captain gives occasional confidence boosting, reassuring, and positive reinforcing comments to other players (demonstrates belief in them-e.g., "runs are around the corner for you Cavanagh").

- Batting Coach interjects with some positive feedback for players regarding last week's match.

- Captain provides goals for players in terms of wanting to be the best batting team in the competition and for every match, making it their aim to only bat once.

This observational data shows that there was very limited coach intervention during the meeting with the assistant coach (batting) only intervening once throughout the fifteen-minute meeting. Across each context, the meetings provided initial direction for players with the aim of enhancing confidence, increasing their focus at training and heightening each player's awareness of team and individual goals for the upcoming match.

The players and coaches also suggested that empowering others meant clearly identifying individual roles within the team and encouraging them to be accountable for their performances. On-field delegation to players was broken down into training and match responsibilities. During competition, for example, empowerment included being in charge of certain tactical areas. In rugby union there were lineout and backline callers, in cricket, the captain organised the bowling attack and fielding positions whilst in league, players were responsible for components of defence or attack. The idea was to increase player accountability for both good and bad performances within their assigned tactical or technical area.

These results demonstrate that giving assistant coaches, other staff and players responsibility for and ownership over what they are doing enhances their focus, commitment and energies towards a desire to achieve personal and team goals. Hence, the delegation of responsibilities helped create an environment where players and coaches felt valued, accepted and respected.

\subsection{Decision-making}

Data analysis revealed that effective coaches must be assertive and take responsibility for decisions made. This means that even with a player-centred or empowerment approach, the participants agreed that the final decision must remain the coaches. Ronnie (rugby union assistant coach) summarised this crucial point:

...the buck [responsibility] ultimately still stops with the coach and I think that is a key area... in the end, decisions have to be made ... they have to make decisions and the players need to understand that and you need to let them know ... And that's one of the most important functions of coaching, particularly for the head coach ... When it comes down to key organisational or key areas, or major decisions, that affect individuals that should be the domain of the coach.

What this suggests is that both coaches and players agreed that under certain circumstances (e.g., final team selections, player recruitment), decision-making should be left to the coaching staff. In the three professional contexts examined however, the extent to which each coach allowed others to make decisions, varied greatly. Only Leopold (rugby league head coach) suggested that too much empowerment was considered ineffective while other players and coaches did not indicate specifically how much effective coaches did or did not allow others to make decisions. Overall, the players and coaches also agreed that one of the most important skills of effective coaching is the ability to make decisions, regardless of the leadership style or coaching strategy employed by the coach. 


\section{Discussion}

According to the perceptions of professional coaches and players in Australia, an effective coach possesses their own personal approach to leadership (coaching philosophy), where various leadership strategies are considered effective. The results reveal that a variety of coaching styles exist, from highly facilitative (empowering) to more autocratic (amiable dictator). It is plausible that perceptions of effectiveness are dependent on the relationships developed between coaches and players as well as the professional context in which they exist. These findings support previous leadership research (e.g. Chelladurai and Carron, 1978; Chelladurai, 1990; Sherman et al., 2000) as the participants in the present study provided examples of key parameters for effective coaching that depended on whether the coach and player views aligned. In fact, attributes from the Multidimensional Model of Leadership (Chelladurai and Carron, 1978; Chelladurai, 1990) highlighted that player satisfaction and performance increases when coaches' behaviours were compatible with those favoured by players. Therefore, it is crucial for effective coaches to employ their own leadership approach but remain cognizant of player preferences for specific leadership styles.

The leadership style exhibited by rugby league coaches indicated a more coach-directed 'teacherstudent' style relationship with players. This approach reflected a more top-down, coach-centred style of coaching whilst their counterparts in cricket and rugby union exhibited a more player-centred or bottom-up model. These findings indicate that contextual factors such as the sports code, professional setting and the age of players may have bearing on the style of leadership displayed. For example, in much the same way as the cricket and rugby union coaches described their role as 'facilitators', the professional Australian Football League head coaches in Kellett (1999) believed that they were facilitators rather than leaders and had a responsibility to empower and facilitate leadership amongst the player group. Here, empowering others was considered essential to gaining player confidence, loyalty, trust and respect which supports studies with professional (Kellett, 1999) and college coaches (Vallée and Bloom, 2005) by confirming the notion that delegating responsibility is advantageous as it makes players and coaches feel valued, accepted and respected in various sporting contexts.

Another potential advantage of the 'facilitative' or 'roaming' leadership style was that it enabled the head coach to observe training action and take players aside to communicate with them individually while other players continued training. This type of scenario also meant that the players were able to receive expert tuition from specialist coaches while the head coach spent more time evaluating player form, attitude and interactions that helped guide weekly selections. Like the expert coaches in Jones et al. (2004), this meant that the coaching staff became more like advisors, mentors and sources of information rather than strictly directing the coaching process.

While all coaches declared that delegating responsibility was important to increase player accountability, the cricket and rugby union coaches believed in bestowing many responsibilities to assistant coaches and the players while the rugby league head coach did not. In addition, it remained unclear as to whether the ideas put forward by the player group needed to be 'activated' or whether just listening to players' ideas was enough to maintain player respect and interest. In a recent study with elite team and individual sport coaches, Potrac (2004) pointed out that while coaches appeared to provide opportunities for athletes to have an input, on occasions they did not really listen to what athletes were saying and ultimately, they would make the decisions. Perhaps players accept that their ideas will not always be converted into reality or this may merely reflect the advent of full-time training within professional sport, where the players are required to spend more time at the training site, and coaches must devise more tasks for player development.

Another point of contention was that at certain times coaches were expected to take responsibility for decision-making (e.g., final team selections, player recruitment), yet the players and coaches did not clearly indicate how much effective coaches should or should not delegate. This reflects an issue raised by Jones and Standage (2006), who suggested that while some coaches were willing to forgo their power, some athletes were unwilling to accept the responsibility and see this as the coach not doing their job properly. Jones and Standage (2006) claimed that many questions continue to exist as to whether coaches can realistically share their leadership function with athletes. This may suggest that 
empowerment could be seen as destabilising, because it has the potential to descend into a mass of conflicting micro politics and breakdown team cohesion. On the contrary, it appears that the participants in this study believe that effective coaches listen to player ideas with the view to developing respectful relationships and a comfortable team environment. Further research is required to confirm how much responsibility is and should be delegated to athletes and to what extent their ideas are implemented by the coaching staff for effective leadership in professional sport settings.

\subsection{Practical Implications}

An important consideration from the results of the current professional contexts is that various leadership styles can be effective, so long as the team environment created is reflective of the coach's leadership style. The leadership approach needs to be aligned, in a collaborative fashion, with the values, beliefs and attitudes of assistant coaches, support staff and players regarding how an effective coach and team should operate. For example, if the players feel that it is the coach's responsibility to direct the team, construct the learning, and make the majority of decisions; as long as the coach communicates that this is how the team will operate, the coaching strategy may be considered effective. Alternatively, if the coaches and players believe in a more player-centred approach, where greater responsibility is placed on the players for decision-making and their learning, then a modern or facilitative approach to coaching may be more effective. The effective coach is therefore someone who can align the coach and player beliefs, regardless of the leadership style they use to try to create an environment that is consistent with the ideals of both parties. Players are more likely to respect the coach, form relationships with them, and want to work hard for them if they (the players) are satisfied with the coach's approach.

One of the concerns with this research includes the small sample size and the varied time of year in which data was collected. Although large and detailed data was gathered, the limited number of teams included in the current research restricted the breadth of views to just three of the professional sports codes in Australia. Being involved with a team or several teams during away fixtures or over an entire season would provide a more detailed in- sight into the varied coaching techniques of coaches across discrete contextual conditions. These are issues that deserve further sport psychology or coaching research with a larger budget.

\section{References}

Bennie, A. (2009). Effective coaching in cricket, rugby league and rugby union: A qualitative investigation involving professional coaches and players from Australia. Unpublished Doctoral dissertation, University of Sydney, Sydney (available at http://hdl.handle.net/2123/5739).

Bennie, A. and O'Connor, D. (2010). Coaching Philosophies: Perceptions from Professional Cricket, Rugby League and Rugby Union Players and Coaches in Australia, Int. J. of Sports Sci. and Coaching, 5(2): 309-320.

Bloom, G. A. (1996). Characteristics, Knowledge, and Strategies of Expert Team Sport Coaches. Unpublished Doctoral dissertation, University of Ottawa.

Chelladurai, P. (1990). Leadership in sports: A review. International Journal of Sport Psychology, 21: 328-354.

Chelladurai, P. and Carron, A. V. (1978). Leadership. Vanier City: Canadian Association for Health, Physical Education and Recreation.

Côté, J. and Gilbert, W. (2009). An integrative definition of coaching effectiveness and expertise. Int. J. of Sports Sci. and Coaching, 4(3): 307-323.

Côté, J., Salmela, J. H., Baria, A., and Russell, S. J. (1993). Organizing and interpreting unstructured qualitative data. The Sport Psych., 7(2): 127-137.

Côté, J. and Sedgwick, W. A. (2003). Effective behaviors of expert rowing coaches: A qualitative investigation of Canadian athletes and coaches. Int. Sports J., 7(1): 62-78.

Jones, R., Armour, K., and Potrac, P. (2004). Sports Coaching Cultures. London: Routledge.

Jones, R. L. and Standage, M. (2006). First among equals: Shared leadership in the coaching context. In R. L. Jones (Ed.). The sports coach as educator (pp. 65-76). London: Routledge.

Kellett, P. (1999). Organisational leadership lessons from professional coaches. Sport Manage. Rev., 2(2): 150-171.

Kidman, L. and Lombard, B., J. (2010). Athlete centred coaching: Developing decision-makers ( $2^{\text {nd }}$ ed.). Auckland: IPC Print Resources.

Lincoln, Y. and Guba, E. (1985). Naturalistic inquiry. New York: Sage.

Merriam, S. B. (1998). Qualitative research and case study applications in education. San Francisco: Jossey-Bass Publishers.

Potrac, P. (2004). Coaches' power. In R. Jones, K. Armour and P. Potrac (Eds.), Sports coaching cultures: From practice to theory. (pp. 150-162). London: Routledge.

Sherman, C. A., Fuller, R., and Speed, H. D. (2000). Gender comparisons of preferred coaching behaviours in Australian sports. J. of Sport Beh., 23(4): 389-407.

Smoll, F. L. and Smith, R. E. (1989). Leadership behaviours in sport: A theoretical model and research paradigm. J. of App. Soc. Psych., 19(18): 1522-1551.

Smoll, F. L., Smith, R. E., Curtis, B., and Hunt, E. (1978). Toward a mediational model of coach-player relationships. Res. Quart., 49: 528-541.

Stake, R. E. (2000). Case studies. In N. Denzin and Y. Lincoln 
(Eds.), Handbook of qualitative research (2nd ed., pp. 435-454). Thousand Oaks: Sage Publications.

Tesch, R. (1990). Qualitative research: Analysis types and software tools. New York: The Falmer Press.

Vallée, C. N. and Bloom, G. A. (2005). Building a successful university program: Key and common elements of expert coaches. J. of App. Sport Psych., 17(3): 179-196.

Vella, S. A., Oades, L. G., and Crowe, T. P. (2010). The application of coach leadership models to coaching practice: Current state and future directions. Int. J. of Sports Sci. and Coaching, 5(3): 425-434.

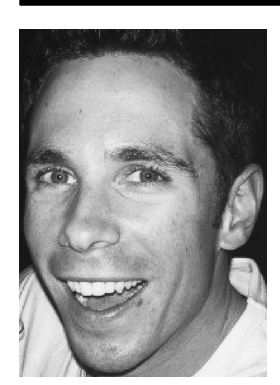

Name:

Andrew Bennie

\section{Affiliation:}

The University of Western Sydney

\section{Address:}

School of Science and Health | The University of Western Sydney | Building BD, Lvl 1, Rm 24b | Werrington South Campus | Locked Bag 1797 | Penrith South DC NSW Australia | 2751 Brief Biographical History:

2005-2010 Faculty of Education and Social Work, University of Sydney

2009 Awarded a PhD from The University of Sydney

2010-Lecturer, Health and Physical Education, University of Western Sydney

Main Works:

-Bennie, A. and O'Connor, D. (2012). Coach-Athlete Relationships in Rugby League, Rugby Union and Cricket: A Qualitative Study of Professional Sport Teams in Australia, International Journal of Sport and Health Science, 10, pp. 58-64

-Bennie, A. and O'Connor, D. (2011). An Effective Coaching Model: The Perceptions and Strategies of Professional Team Sport Coaches and Players in Australia, International Journal of Sport and Health Science, 9, 98-104

-Bennie, A. (2011). Coaching and adherence issues in youth sport. In S. Georgakis and K. Russell. Youth Sport in Australia, p. 211-228 Sydney: Sydney University Press.

-Bennie, A. and O'Connor, D. (2010). Coaching Philosophies: Perceptions from Professional Cricket, Rugby League and Rugby Union Players and Coaches in Australia, International Journal of Sports Science and Coaching, 5(2), 309-320.

Membership in Learned Societies:

Australian Council for Health and Physical Education Research, Australian Track and Field Coaches Association 